\title{
Moral Symbols: A Necklace of Garlic against Unethical Requests
}

\author{
Sreedhari D. Desai ${ }^{\text {a1 }}$ \\ $\&$ \\ Maryam Kouchaki ${ }^{\mathrm{b}}$
}

The authors gratefully acknowledge comments and helpful suggestions from Max Bazerman, Arthur Brief, Mahzarin Banaji, Kristina Diekmann, Deepak Malhotra, Joshua Margolis, Fred Rhodewalt, Kristin Smith-Crowe, Harris Sondak, Francesca Gino, Deidra Schleicher, Chia-Jung Tsay, Ann Tenbrunsel, Lawrence Lessig, Abigail Brown, Jeffrey Edwards, Alan R. Davison, Abhijeet Vadera, Alison Fragale, Sunita Sah, David Hofmann, and Aaron Swartz for their suggestions and insightful comments on earlier drafts. This research was supported by the following fellowships offered to the first author: Mariner S. Eccles Fellowship at the University of Utah, the Program on Negotiation Fellowship at the Harvard Law School, the Edmond J. Safra Center for Ethics Fellowship at the Harvard University, the Women and Public Policy Program Fellowship at the Harvard Kennedy School of Government, and the Collins Dawson Endowment at the University of North Carolina.

${ }^{a}$ Assistant Professor, Kenan-Flagler Business School, University of North Carolina at Chapel Hill, Chapel Hill, NC 27599, United States. E-mail: sreedhari_desai@kenan-flagler.unc.edu \&

Visiting Assistant Professor, Fuqua School of Business, Duke University, Durham, NC 27708, United States. Email: sd286@duke.edu

${ }^{\mathrm{b}}$ Assistant Professor, Kellogg School of Management, Northwestern University, Evanston, IL 60208, United States. Email: m-kouchaki@kellogg.northwestern.edu

${ }^{1}$ Corresponding author. E-mail: sreedharidesai@gmail.com. 


\section{BIOGRAPHIES}

Sreedhari D. Desai (sreedharidesai@gmail.com) is an assistant professor of organizational behavior at the Kenan-Flagler Business School, University of North Carolina at Chapel Hill, and also a visiting assistant professor of management and organizations at the Fuqua School of Business, Duke University. She received her PhD in management from the David Eccles School of Business, University of Utah. Her research focuses broadly on ethics, including issues related to procedural fairness, income inequality, gender diversity, and prosocial behavior.

Maryam Kouchaki (m-kouchaki@kellogg.northwestern.edu) is an assistant professor of management and organizations at Kellogg School of Management, Northwestern University. She received her PhD in management from the David Eccles School of Business, University of Utah. Her research focuses on decision making and ethics. 


\begin{abstract}
This paper investigates whether by exposing superiors to moral symbols subordinates can discourage their superiors from asking them to perform unethical acts. Findings from five laboratory studies and one organizational survey study demonstrated that exposure to moral symbols displayed by the subordinates dissuades superiors from both engaging in unethical behaviors themselves and asking their subordinates to engage in unethical behavior. This paper shows that the display of moral symbols leads to two main consequences of (1) the activation of the concept of morality and increases in individuals’ moral awareness to decrease unethical behavior, and (2) eliciting inferences about the moral character of the displayer to lower the likelihood of that person being subjected to unethical directives. Additionally, our findings demonstrate that moral symbols influence ethical decisions without provoking hidden backlash effects against those who display them. In sum, our findings show that followers can serve as a form of social influence to guide their leader's behavior and reduce the occurrence of unethical acts in the workplace.
\end{abstract}

Keywords: ethics, unethical request, moral symbol, moral awareness, moral character, backlash 
When the NationsBank scandal came to light several years ago, securities brokers who used to work there revealed that their superior had asked them to peddle high risk mutual funds to clients about to retire who specifically wanted to avoid investing in such funds (Tahmincioglu, 2000). The brokers realized that what they were being asked to do was unethical but they felt caught between their principles and payday. Indeed, according to a National Business Ethics Survey, in 2013, 9\% of employees perceived pressure to compromise ethics standards in order to do their jobs (Ethics Resource Center, 2013). Now, imagine yourself as a confidant to one such employee; what helpful suggestions might you offer? Note that retaliation against employees reporting misconduct was at 21\% in 2013 (Ethics Resource Center, 2013); thus challenging or confronting the boss would be a difficult proposition. How can employees change organizational authorities' behavior and discourage unethical directives?

Management scholars, as well as, managers, employees, and the general public tend to focus on the question of how leaders influence followers’ ethical behaviors. However, an equally important and interesting question, which has been relatively underexplored is, "How followers can change a leader's ethical decisions and behavior?” Whereas existing research for the most part has taken a top down perspective (e.g., Mayer, Aquino, Greenbaum, \& Kuenzi, 2012; Palmer, 2008; Treviño \& Brown, 2004) and examined how organizational authorities can influence employees, we focus on a bottom up perspective and examine how employees may influence superiors without incurring their wrath. We are particularly interested in examining how employees can discourage organizational authorities from asking them, in particular, to commit unethical acts.

Just as wearing a necklace of garlic can help ward off mythological vampires (Stoker, 1897/2011), in this paper, we examine the possibility of offering subordinates a safe way in 
which they may prevent their superiors from asking them to perform unethical acts. Specifically, we investigate the idea that by exposing their superiors to moral symbols ${ }^{1}$ such as words, images, or mundane objects, subordinates may discourage unethical acts overall and also dissuade superiors from asking them to engage in unethical acts. An emerging stream of research in moral psychology and behavioral ethics shows that accessibility of moral constructs influences ethical decisions, judgments, and behaviors (Aquino, Freeman, Reed, Lim, \& Felps, 2009; Gunia, Wang, Huang, Wang, \& Murnighan, 2012; Mazar, Amir, \& Ariely, 2008). As such, the use of moral symbols while interacting with leaders could be a source of social influence for followers to discourage unethicality. Individuals’ ethical decision making has been shown to depend on the social influence they are exposed to (Gino, Ayal, \& Ariely, 2009; Pitesa \& Thau, 2013; Sonenshein, 2007; Treviño, 1986).

Our objective in this article is to propose and empirically test a theoretical model that explains how and why in interpersonal contexts-including subordinate-supervisor relationships in spite of the inherent power asymmetries - the display of moral symbols, even though subtle in nature, decreases unethical behaviors. This paper focuses on subordinates’ moral choices and behaviors and their role in helping supervisors’ ethical behaviors in the organizational context. We draw from a dual-system or synthetic framework for morality (Cushman, Young, \& Hauser, 2006; Greene, Nystrom, Engell, Darley, \& Cohen, 2004; Haidt, 2001; Moore \& Gino, 2015)— which emphasizes the role of both automatic and controlled processes in moral judgment and behavior-to suggest that moral symbols (1) make moral constructs accessible and increase

\footnotetext{
${ }^{1}$ Note that our construct of moral symbol is a subset of a similar sounding construct called moral identity symbolization which refers to a dimension of moral identity that causes people to demonstrate their possession of moral traits through moral actions or objects (Aquino \& Reed, 2002). Whereas moral identity symbolization also includes behaviors such as involvement in activities that communicate to others one's moral characteristics (e.g., hobbies), our definition of moral symbols is slightly narrower to include moral objects (e.g., moral accessories, images, quotes).
} 
moral awareness, and (2) elicit inferences about the moral character of the displayer. This latter aspect, in particular, would serve the purpose of shielding the displayer from being asked to engage in unethical behaviors as a result of perceived moral character.

This paper makes a number of important contributions. First, we extend the business ethics literature by examining socio-psychological processes that encourage ethical behavior. Second, unlike most of existing research that has taken a top down perspective, we examine a bottom up social influence phenomenon and examine the importance of subordinates' choices and behaviors in influencing authorities' ethical behaviors. Third, this paper extends prior work on moral identity in an important way by examining moral displays in an interpersonal context. Fourth, whistle-blowing literature has shown that perceived personal risk and, in particular, fear of retaliation, are the primary reasons for employees being generally reluctant to report workrated transgressions (Miceli, Near, \& Dworkin, 2013). Employees are often penalized for reporting or speaking up about unethical conduct (Mesmer-Magnus \& Viswesvaran, 2005). We contribute to this work by examining the consequences of exposing one's superior to moral symbols. We demonstrate that the use of moral symbols does not bring hidden backlash effects against those who display moral symbols. It changes the perception of the situation and elicits inferences about the moral character of the follower, both guiding the leader's behavior. Thus our work offers a way to help employees to say "no” in a non-conflictive and preemptive manner.

\section{THEORETICAL BACKGROUND AND HYPOTHESES}

Moral symbols are associated strongly with moral concepts in people’s minds; they could be material objects such as a cross that have come to acquire moral meaning and value through ritualized behavior (see Dittmar, 1992; Miller, 1998). Another example of symbols could be 
posters of moral prototypes (Walker \& Hennig, 2004) such as Mahatma Gandhi who have come to be recognized in the collective conscious of a given society for their ethical practices. Alternately, they could be explicit quotations exhorting people to be virtuous. Research has shown that when symbols and concepts are closely associated, on being exposed to the symbol, the related concept automatically becomes more accessible to the mind (see Bargh, 1994, 2007). For instance, on seeing a gun, one may not only automatically think of violence but also become more likely to behave aggressively (Anderson, Benjamin, \& Bartholow, 1998). In fact, past research has shown that moral primes manipulate the accessibility of moral constructs and influence subsequent moral choices and behavior (Aquino et al., 2009; Mazar et al., 2008; Welsh \& Ordonez, 2014). That is, if certain symbols (for example, words such as "honest,” or objects such as a “cross”) come to embody moral meanings (such as "honorable” or "godliness”) then exposure to such symbols increases the accessibility of the construct of morality and individuals’ construal of the situation as a moral one (Kay, Wheeler, Bargh, \& Ross, 2004; Kouchaki, SmithCrowe, Brief, \& Sousa, 2013).

Of particular relevance to our interest on the effects of moral symbols on ethical behavior is the role that both automatic and deliberate processes play in moral judgment and behavior. We suggest that followers interacting with their leaders can use moral symbols as a source of social influence to discourage unethicality in their organizations through both automatic and deliberate processes. A longstanding debate in moral psychology is the question whether moral judgment and behavior arise from deliberate or automatic processes. Scholars following the tradition of rational decision making have emphasized the role of deliberate, conscious reasoning and considered moral judgment and behavior to be an outcome of cognitive, deliberate processes (Kohlberg, 1981; Rest, 1986). Others have challenged this conscious reasoning perspective and 
argued that there may be automatic, reflexive and intuitive aspects to ethical decision making (e.g., Greene \& Haidt, 2002; Haidt, 2001). For example, Reynolds (2006) emphasized the role of automaticity and non-conscious priming in his neurocognitive model of moral decision-making built around the concept of "prototypes" that are activated nonconsciously on exposure to relevant environmental cues. As per his model, one way the human mind identifies moral issues is by making use of prototypes that are based on past experience with stimuli. Prototypes can represent sounds, language, objects, scenes, situations, concepts, and even complex social interactions. Based on his model, moral symbols can elicit moral cognition nonconsciously.

Adopting a middle ground, some researchers have endorsed a dual-system perspective and have argued that both deliberate reasoning and automaticity play a role in moral judgment and behavior (Cushman et al., 2006; Greene, 2009; Haidt, 2001; Monin, Pizarro, \& Beer, 2007). Here, we do not intend to engage in a debate of which type of processing plays a more important role; we concur with Moore and Gino’s (2015) position that it may be “more accurate to call the model "synthetic” (Greene et al., 2004) rather than dual-process, since rational and nondeliberative processes appear to be co-dependent and work cooperatively as often as they compete” (p. 245).

Of particular relevance to understanding the impact of moral symbols on supervisors’ ethical decision making is the two-stage "signaling-processing” model put forth by Tenbrunsel and Messick (1999). According to this model, in Stage 1 of decision making, environmental cues send signals which influence the way a situation is perceived, and consequently affect the construal of the situation and the decision frame that is adopted. In Stage 2, the adopted perception of the situation offers a lens through which the situation is perceived as predominantly having economic or social considerations. For example, the presence of sanctions 
in an environment may send an implicit message of mistrust to employees in Stage 1 and make them perceive the situation as one that warrants attention to ways of deflecting penalties, as opposed to a situation requiring cooperation, and thus, might promote the use of a competitive decision frame (Tenbrunsel \& Messick, 1999). In Stage 2, the competitive decision frame adopted (even though it may have been adopted nonconsciously) may result in conscious thoughts focused on self-interest, which lead to competitive behavior. Importantly, Tenbrunsel and Smith-Crowe (2008) argue that decision frames inform moral awareness. Compared to business or legal frames, under the influence of an ethics frame, decision makers are morally aware. Thus, if the situational context in Stage 1 causes decision-makers to adopt an ethics frame, subsequently in Stage 2, they are morally aware and social considerations play a role in decision making.

In keeping with the two-stage model of ethical decision making, we argue that exposure to moral symbols displayed by one’s subordinates is likely to increase moral awareness, which in turn, affects ensuing ethical behavior. Relevant to our theorizing, the accessibility of the construct of morality as a consequence of exposure to moral symbols (Stage 1) increases moral awareness (Stage 2) by making people recognize that the situation at hand may contain "moral content and legitimately can be considered from a moral point of view” (Reynolds, 2006). Importantly, we believe that regardless of whether there is a division between automaticity and deliberation and where it is placed, or whether both processes are co-dependent and work cooperatively, both conscious reasoning and automaticity can play a role in determining ethical behavior after exposure to moral symbols. It is possible that the accessibility of the construct of morality may result in conscious thoughts focused on morality-permitting but not guaranteeing a role for conscious reasoning. It is also possible that if subordinates display moral symbols, their 
superiors may consciously register the presence of moral symbols but not necessarily be aware of the impact of such symbols on their cognitive processes. And, it is also very likely that exposure to moral symbols automatically makes the construct of morality accessible and increases moral awareness, but individuals may not necessarily be aware of the impact of such symbols on their interpretation and construal of the situation (their moral awareness). Overall, we predict the following:

Hypothesis 1: Supervisors exposed to moral symbols of their subordinates are less likely to engage in unethical behavior than those not exposed to such symbols.

Hypothesis 2: Moral awareness mediates the relationship between exposure to moral symbols displayed by subordinates and likelihood of a superior to engage in unethical behavior.

For our first hypothesis we relied on the activation of the concept of morality in general and the increase in one's moral awareness (i.e., to construe the situation as one with moral implications), to influence ethical behavior. However, in addition to increased moral awareness, in an interpersonal context potentially laden with asymmetrical power relationships, we propose that the display of moral symbols may also elicit inferences about the moral character of the displayer and that is likely to influence the supervisor's behavior towards the displayer in particular (See Figure 1). This is in line with prior theoretical arguments conceptualizing ethical leadership as a social learning process (Brown et al., 2005; Brown \& Treviño, 2006), that is, followers can impact attitudes, values and behaviors of their leaders. Specifically, by observing an exceptional follower's (i.e., model’s) behavior, the leader may come “to identify with the model, internalize the model's values and attitudes, and emulate the modeled behavior” (Brown \& Treviño, 2006). Theoretically, this is an important distinction we make because the literature 
on moral awareness does not differentiate between the behavior towards the displayer and any other subordinate, while our argument proposes that displaying moral symbols will prevent the superior from asking the displayer, in particular, to engage in unethical behavior. As noted, we suggest that the use of moral symbols by a follower can elicit inferences about the high moral character of that follower in addition to increasing moral awareness and thus, the follower can serve as a form of social influence to guide the leader's behavior and reduce the occurrence of unethical acts in the workplace in addition to shielding herself/himself from unethical requests.

\section{[Insert Figure 1 Here]}

Generally, people are known to make social judgments about others based on the objects they buy and own, the clothes they wear, the type of furnishings they have, the kind of music they listen to, and so on (e.g., Belk, 1988; Elsbach, 2004). In other words, various objects and abstract ideas owned and displayed by a person signal to others how important a particular identity associated with these symbols are to that person's overall self-concept (Gollwitzer, 1986; Laughlin, 1970). In the workplace, people make inferences about their coworkers, subordinates, and bosses, based on cues such as how the office is laid out, how personalized the space is, how cluttered the desk is, what their signature looks like, and so forth (Elsbach, 2003, 2004; Elsbach \& Pratt, 2007). Although there are no studies linking the presence of moral symbols to inferences about a person's moral character, researchers have found that organized desks, good lighting, cheerful décor, and the presence of books lead observers to infer that the occupant is conscientious, and unwilling to bend the rules (Gosling, Jin Ko, Mannarelli, \& Morris, 2002). It is therefore reasonable to assume that moral symbols such as religious objects and quotations regarding honor at the bottom of emails may also lead observers to form impressions about a person’s moral character, behavior, and ethical preferences. 
Moral symbols might lead bosses to infer that the subordinate displaying the symbol has high ethical standards; thus, even if the boss chooses to engage in unethical acts, he/she may require a subordinate other than the one perceived as high moral character to perform the unethical tasks. Indeed, according to the moral foundations theory, people have an intuitive desire to venerate and cherish purity and protect from desecration the symbols that signify purity (Graham, Nosek, Haidt, Iyer, Koleva, \& Ditto, 2011). Literature stemming from cultural anthropology as well as social psychology suggests that people intuitively consider it immoral to defile pure objects or beings such as harming the innocence of children or disrespecting moral exemplars (Gino \& Desai, 2012; Shweder, Mahapatra, \& Miller, 1987; Shweder \& Much, 1991). Often, such desecration evokes feelings of moral disgust. As such, it might be perceived as an added layer of moral violation to issue an unethical directive to an employee perceived as having high moral character. Thus superiors may feel uncomfortable issuing an unethical directive to a subordinate displaying moral symbols because of perceived high levels of moral character.

Additionally, issuing unethical directives to a person with high moral character may induce feelings of moral accountability towards that person. Accountability is defined as the anticipation of being evaluated, of being required to justify one's beliefs or actions to another individual, or the apprehension of being judged (Lerner \& Tetlock, 1999). Importantly, such expectations need not necessarily be explicit; they can comprise of implicit feelings that one might be judged for the choices one makes or the way one behaves (Lerner \& Tetlock, 1999). It is possible that when superiors form moral attributions regarding a subordinate due to exposure to moral symbols, they likely imagine how such an ethical employee would judge them if he or she were to find out how unethical the request was. Previous work has demonstrated that accountability modifies thought processes such that people become more critical of their future 
actions (Desai \& Kouchaki, 2015; Lerner \& Tetlock, 1999). Thus, feelings of accountability may make unethical superiors avoid issuing the directive to an employee perceived as high moral character.

Furthermore, there may be a concern that a subordinate with high moral character may follow his/her internal moral principles and choose not to comply with the unethical request. Such disobedience could either take the form of not following the instructions or, possibly, motivating the subordinate to complain to higher authorities regarding the unethical nature of the task assigned or even blow the whistle. As such, superiors may avoid issuing unethical directives to a subordinate high in moral character. In sum, there are various reasons why being exposed to a moral symbol and inferring that a subordinate has high moral character might dissuade superiors from issuing unethical directives to that particular subordinate.

Hypothesis 3: By exposing a superior to moral symbols, a subordinate will have a better chance of preventing the superior from asking him/her (i.e., the subordinate displaying the moral symbol) to engage in unethical behavior.

Hypothesis 4: Perceived high moral character of the subordinate displaying moral symbols mediates the relationship between display of such symbols and the likelihood of the superior asking the displayer to engage in unethical behavior.

In sum, by displaying moral symbols, subordinates can reduce their superiors’ unethical behavior and discourage their supervisors from instructing them, especially, to engage in unethical acts.

\section{OVERVIEW OF STUDIES}

We conducted six studies - five laboratory studies and a survey study of subordinatesupervisor dyads — to test our theory. First, in Studies 1 and 2, we tested the effect of display of 
different moral symbols on leaders' moral behavior and their choice of subordinate. In Study 3, we examined if moral symbols prevent only unethical requests or any request directed at the displayer. In Study 4, we examined if exposure to moral symbols reduces unethical behavior of bosses and if moral awareness mediates this effect. In Study 5, we used a simulation involving organizational decision-making to further test the effect of display of moral symbols on leaders’ moral behavior and their choice of subordinate, and also examine the mediating role of perceived moral character in averting unethical requests directed at the displayer. In Study 6, we tested our hypotheses with data from a survey of subordinate-supervisor dyads in India using pictures of gods and other religious icons as examples of moral symbols frequently used in workplace in that culture.

\section{STUDY 1}

In Study 1, we test Hypotheses 1 (overall unethical behaviors) and 3 (likelihood of the superior asking the subordinate displaying the moral symbol to engage in unethical act) using a measure of dishonesty, namely, the deception game (Gneezy, 2005). Additionally, we used a post-experimental questionnaire as part of the debriefing to assess participants’ suspicion and examine what they think the purpose of the study was, or what was their impression of the situation depicted in the study.

\section{Methods}

Sample and Design. One hundred and forty-eight college students (81 men, $M_{\text {age }}=$ 20.64, $S D=3.18$ ) from a university in United States participated in this study for pay. In addition to participation payment, participants had the opportunity to earn $\$ 4$ or $\$ 9$ based on the outcome of an economic game. The study employed a 2 condition (Moral symbol: present vs. absent) between subjects design. 
Procedure. Participants were informed that as part of a study on decision-making in virtual teams, they would be paired with two other participants to form a virtual team to jointly play the role of Team 1 . They were further told they would receive introductory emails from their team members and would respond to them using a messaging system internal to the experiment. Additionally, one member of each virtual team would be assigned to the role of "team leader."

All participants were then assigned to play the role of their team's leader. The other two "members" were fictitious people, Pat and Sam, who would send short emails to the team leader briefly introducing themselves as members 2 and 3 . At the bottom of the introductory email sent to the team leader, Pat's email either included a moral quote ("Better to fail with honor than succeed by fraud") or there was no quote to serve as a moral symbol.

Next, participants played a modified version of a deception game (Gneezy, 2005) in which they had an opportunity to deceive their opponent team. However, we did not allude to any ethics-related words and told participants that they would simply play a game with another team. Specifically, they were then given the following instructions:

"In this game, your team (Team 1) and the other team (Team 2) will initially be given $\$ 30$ each. At the end of the game, two monetary payments are possible. The payments for Team 1 and Team 2 will depend on the payment option that Team 2 chooses. Team 2 will be given two payment options to choose from, but only the leader of Team 1 will know the actual amounts of each payment option. Here is an example of the information that might be available to the leader of Team 1 :

Sample Payment Option A: If this option is chosen, Team 1 will lose $\$ 1$ and Team 2 will lose $\$ 4$.

Sample Payment Option B: If this option is chosen, Team 1 will lose $\$ 4$ and Team 2 will lose $\$ 1$.

The leader of Team 1 will ask one of the members on the team to communicate to Team 2 one of the following messages:

Sample Message 1: Payment option A will result in the most money for you (i.e., Team 2). 
Sample Message 2: Payment option B will result in the most money for you (i.e., Team 2).

Team 2 will then decide which payment option to choose, and based on Team 2's decision, Team 1 and Team 2 will receive the dollar amounts specified in the payment option chosen and the money will be divided equally between team members. At no time Team 2 will know the values of the different payment options or how much money Team 1 received in the end as a consequence of the payment option chosen by Team 2. At the end of the experiment, each team's payment will be divided equally between its members."

Note that participants were informed that only they, as the leader of Team 1, would be privy to the dollar amounts contained in payment options A and B; rest of their team (Sam and Pat) would not have access to this information. Moreover, after deciding which message to send to Team 2, the leader would select either Pat or Sam to communicate the message to Team 2. The two actual payment options presented to the participants were:

Payment option A: If this option is chosen, Team 1 will lose \$18 and Team 2 will lose \$3. Payment option B: If this option is chosen, Team 1 will lose \$3 and Team 2 will lose \$18.

The leader of Team 1 (the participant) then had to decide whether to send the other team an honest message (i.e., Message 1) or a deceptive message (i.e., Message 2) by one of his/her team members (Pat or Sam). Sending the truthful message would likely cause their team to lose $\$ 18$; lying and sending the deceptive message would likely cause their team to lose only $\$ 3$. Thus, there was a clear financial incentive to lie.

Note that the way the study was set up, the leader knew that the subordinate communicating the message would have no way of knowing whether the message he/she was asked to communicate was honest or not, and thus, irrespective of the decision they (the leaders) made, the leaders' moral reputation would be intact. Lastly, note that the experimental design incorporated a "loss frame," that is the two options A and B were framed as resulting in a loss of $\$ 18$ or $\$ 3$, as opposed to a gain of $\$ 12$ or $\$ 27$. Loss frames have been shown to increase 
unethical behavior (e.g., Kern \& Chugh, 2009), and thus, using a loss frame provided a more conservative test of the effectiveness of moral symbols.

After choosing one of the messages to be communicated and the person to communicate the message, participants were asked to respond to a few questions designed to examine if participants were aware of the purpose of the exercise, i.e., whether the manipulation was having a non-conscious effect on behavior (Shantz \& Latham, 2009): (i) What do you think is the purpose of the experiment? (ii) What do you think the experiment was trying to uncover? (iii) Did you think any of the emails influenced your decisions? (iv) If so, how? and (v) Did anything in the instruction packet affect what you did? An examination of participants' responses to the post-experimental questionnaire reveals that none of the participants expressed any suspicion or correctly identified the study’s hypotheses. They claimed that their decision making was their own and uninfluenced by any situational cues. In other words, even though some participants may have registered the presence of a moral symbol, they were unaware of its effects on their cognition and behavior.

\section{Results and Discussion}

Reduction in overall unethical behavior. First, we examined if exposure to a moral symbol led to decreases in overall unethical behavior in the form of lower incidence of communication of the deceptive message. Indeed, the percentage of participants who chose to communicate the deceptive message to the opposing team varied based on whether they had been exposed to a moral symbol, $\chi^{2}(1,148)=4.61, p<.05$. In the control condition, 63.5 percent of participants (47 out of 74) chose to communicate a deceptive message. This percentage was significantly lower in the moral symbol condition, in which 45.9 percent of participants (34 out 
of 74) chose to communicate a deceptive message. In other words, the display of a moral symbol reduced the overall instances of unethical behavior of the leader, thus supporting Hypothesis 1.

Protection for displayer of the moral symbol. To examine whether a moral symbol protected the individual displaying the symbol, that is, whether those team leaders who decided to engage in deceptive behavior were less likely to ask Pat (the team member who displayed the moral symbol) to communicate the untruthful message, we examined the subset of leaders who selected the deceptive message. Indeed, among those who decided to communicate a deceptive message, exposure to the moral symbol had a significant effect on whether they chose Pat (with moral symbol) or Sam (no moral symbol) to deliver the message, $\chi 2(1,81)=8.19, p<.01$. In the control condition, 55.3 percent of participants (26 out of 47) asked Pat to communicate the deceptive message. This percentage was significantly lower in the moral symbol condition, in which only 23.5 percent of participants (8 out of 34) asked Pat to communicate the deceptive message. In other words, exposing a leader to moral symbols did prevent the superior specifically from asking the displayer to carry out the unethical action if they chose to do so, thereby supporting Hypothesis 3.

As noted above, an examination of participants' responses to the post-experimental questionnaire did not reveal any awareness of the purpose of the experiment. This observation coupled with the rest of the findings suggest that indeed, displaying moral symbols serves as a necklace of garlic and prevents those in authority from asking the particular subordinate to execute unethical tasks even if they (the superiors) choose to engage in unethical acts.

As shown, unethical leaders chose not to ask Pat to convey the dishonest message to the other team. Remember that in this study the leader knew that the subordinate communicating the message would not know whether the message he/she was asked to communicate was honest or 
not and their moral reputation would be intact. In other words, the experimental design made it easy for leaders to behave unethically and yet, those in the experimental condition were less likely to ask their subordinate to communicate the deceptive message. These results suggest that there might be a psychological disincentive associated with asking a person perceived to be ethical to carry out an unethical directive.

\section{STUDY 2}

In Study 1 we used a moral quote as the example of moral symbols. The purpose of Study 2 was to examine the generalizability of the results obtained in previous study by using a different manipulation of moral symbol, namely a T-shirt advertising a website, "YourMorals.Org” (experimental condition) or "YourMoney.Com” (control condition).

\section{Methods}

Sample and Design. We recruited one hundred and twenty eight individuals from United States to participate in an online study through Amazon’s Mechanical Turk website (MTurk). Ten individuals who failed to follow instructions, failed attention checks, or did not respond to questions regarding the study variables of interest were excluded from analyses. The final sample consisted of 118 participants (53 men, $\left.M_{\text {age }}=33.9, S D=11.4\right)$. The study employed a 2 condition (Moral symbol: present vs. absent) between subjects design.

Procedure. Participants were informed that they would participate in a study examining virtual interactions. As part of the study they would choose avatars, that is, icons or figures representing a particular person in the digital world such as internet forums. First, they were asked to create their own avatars by specifying details such as gender, hair color, clothes, and so forth. They had numerous options to choose from for the various categories, including T-shirts. Note that they had to choose amongst T-shirts that had "StateFarm.com”, "MetLife.com”, 
"Geico.com" and so forth printed on them². The cover story for using these labels was that the study was sponsored by these companies. Next, they were informed that as part of a study on decision-making in virtual teams, they would be paired with two other participants to form a virtual team to jointly play the role of Team 1 . They were further told they would view the avatars of their team members and would communicate with them using a messaging system internal to the study. Additionally, one member of each virtual team would be assigned to the role of "team leader."

All participants were then assigned to play the role of their team's leader. The other two “members” were fictitious people, Pat and Sam, whose avatars were displayed to the team leader as members 2 and 3. Pat's avatar wore a T-shirt that either advertised a website called “YourMorals.Org” (experimental condition) or “YourMoney.Com” (control condition). Sam’s avatar wore a T-shirt that advertised “ChillPill.Com” in both conditions.

Next, participants played the same decision making game as in Study 1 in which they had an opportunity to deceive the opposing team by sending a dishonest message, and had to decide whether Pat or Sam would communicate the message.

\section{Results and Discussion}

Reduction in overall unethical behavior. First, we examined if exposure to a moral symbol led to decreases in overall unethical behavior in the form of lower incidence of communication of the deceptive message. Indeed, the percentage of participants who chose to communicate the deceptive message to the opposing team varied based on the exposure to moral symbol manipulation, $\chi^{2}(1,118)=4.88, p<.05$. In the control condition, 60.3 percent of participants (35 out of 59) chose to communicate a deceptive message. This percentage was

\footnotetext{
${ }^{2}$ However, none of the T-shirts presented to them had "YourMoney.org” or "YourMorals.org” printed on them.
} 
significantly lower in the moral symbol condition, in which 39.0 percent of participants (23 out of 59) chose to communicate a deceptive message. In other words, the display of a moral symbol reduced the unethical behavior of the leader, further supporting Hypothesis 1.

Protection for displayer of the moral symbol. To examine whether the moral symbol protected the individual displaying the symbol, that is, whether those team leaders who decided to engage in deceptive behavior were less likely to ask Pat (the team member who displayed the moral symbol) to communicate the untruthful message, we examined the subset of leaders who selected the deceptive message. Among those who decided to communicate a deceptive message, exposure to the moral symbol had a significant effect on whether they chose Pat (with moral symbol) or Sam (no moral symbol) to deliver the message, $\chi 2(1,58)=4.50, p<.05$. In the control condition, 54.3 percent of participants (19 out of 35) asked Pat to communicate the deceptive message. This percentage was significantly lower in the moral symbol condition, in which only 24.0 percent of participants (6 out of 23) asked Pat to communicate the deceptive message. In sum, exposing a leader to moral symbols did prevent the superior specifically from asking the displayer to carry out the unethical action if they chose to do so, (Hypothesis 3).

\section{STUDY 3}

Thus far, we have examined the effect of moral symbols in discouraging superiors from asking subordinates to do something unethical. Yet, it is still unclear whether the display of moral symbols makes leaders less likely to make unethical requests of the moral symbol displayer, or less likely to make any kind of request. In other words, might the garlic necklace simply be keeping the manager away such that they would avoid the subordinate even for ordinary tasks without ethical implications? To further explore this question, we conducted a 
study in which we examined if moral symbols prevented superiors from asking the displayer to engage in a task if it was unethical, or even if it was a neutral task.

\section{Methods}

Sample and Design. We recruited two hundred and ten individuals from United States to participate in an online study through Amazon’s Mechanical Turk website (MTurk). Three individuals who failed to follow instructions, failed attention checks, or did not respond to questions regarding the study variables of interest were excluded from analyses. The final sample consisted of 207 participants (98 men; $M_{a g e}=35.9$ years, $\left.S D=12.6\right)$. The study employed a 2 (Moral symbol: present vs. absent) by 2 (Domain: ethical dilemma vs. no dilemma) between subjects design.

Procedure. Similar to Studies 1-2, participants were informed that they were taking part in a study on decision-making in virtual teams in which they would be paired with two other participants to form a virtual team to jointly play the role of Team 1 . Participants received introductory emails from two fictitious team members (Zoya and Masha) and were assigned to play the role of their team's leader. At the bottom of the introductory email sent to the team leader, Zoya's email either included the moral quote used in Study 1 ("Better to fail with honor than succeed by fraud”) or there was a neutral quote, "Success and luck go hand in hand.” 3

Next, participants played a game (Gneezy, 2005) in which they had an opportunity to communicate with their opponent team and possibly deceive them. However, based on random assignment, participants either were assigned to play a game involving an ethical dilemma (i.e.,

\footnotetext{
${ }^{3}$ We ran a pilot study with a separate group of participants $(n=50)$ with a within participant design and asked everyone to rate the two quote on a number of characteristics in a random order on a 7-point Likert scale ranging from 1 (very slightly or not at all) to 7 (extremely). The results confirmed that people rated the moral quote as more moral $(M=6.16, S D=1.03)$ and virtuous $(M=5.98, S D=1.19)$ than the neutral quote $(M=3.71, S D=1.54 ; M=$ 3.73, $S D=1.48)$, both $p<.001$. Importantly the neutral quote was rated as more neutral $(M=4.88, S D=1.62)$ and unemotional $(M=4.63, S D=1.44)$ than moral quote $(M=2.92, S D=1.49 ; M=4.63, S D=1.44)$, both $p<.001$.
} 
the deception game where it was profitable to lie), or a neutral game in which the two payment options yielded identical payoffs to the two teams (i.e., where there was no dilemma involved). Specifically, the two payment options presented to the participants in the ethical dilemma condition were:

Payment option A: If this option is chosen, Team 1 will gain 75 cents and Team 2 will gain 15 cents.

Payment option B: If this option is chosen, Team 1 will gain 15 cents and Team 2 will gain 75 cents.

And, the two payment options presented to the participants in the no dilemma condition were:

Payment option A: If this option is chosen, Team 1 will gain 15 cents and Team 2 will gain 15 cents.

Payment option B: If this option is chosen, Team 1 will gain 75 cents and Team 2 will gain 75 cents

The leader of Team 1 (the participant) then had to decide whether to send the other team a message communicating that Option A would yield a better outcome to the opponent (i.e., Message 1) or that Option B would yield superior outcome (i.e., Message 2) by one of his/her team members (Zoya or Masha). In the ethical dilemma condition, there was a clear financial incentive to lie whereas in the no dilemma condition, there was no conflict between ethics and financial incentives. Note that in this study we used a different set of names (Zoya and Masha) to test our hypotheses to ensure the observed effects in prior studies are not driven by the names chosen (Pat and Sam).

\section{Results and Discussion}

To examine whether displaying the moral symbol caused the leader to treat the displayer any different from the non-displayer, we first examined the no-dilemma condition. In the nodilemma condition, all participants communicated the message that maximized both teams’ 
payoff, i.e., Message 2. Exposure to the moral symbol had no effect on whether they chose Zoya (who displayed a moral symbol) or Masha (who displayed no moral symbol) to deliver the message, $\chi 2(1,102)=0.13$, n.s.; 58 percent of participants (29 out of 50) asked Zoya to communicate the message in the control condition whereas 61.5 percent (32 out of 52) asked her in the moral symbol condition.

Reduction in overall unethical behavior. In the ethical dilemma condition, 44.8 percentage communicated the deceptive message that maximized their team's payoff, i.e., Message 1. Exposure to the moral symbol had a main effect on whether participants selected the deceptive message, $\chi 2(1,105)=5.05, p<.05 ; 55.8$ percent of participants (29 out of 52) selected the unethical message in the control condition whereas only 34 percent (18 out of 53) selected the unethical message in the moral symbol condition.

Protection for displayer of the moral symbol. We examined whether those team leaders who decided to engage in deceptive behavior were less likely to ask Zoya to communicate the untruthful message when she displayed the moral symbol. We looked at the subset of leaders who selected the deceptive message. Indeed, among those who decided to communicate a deceptive message, exposure to the moral symbol had a significant effect on whether they chose Zoya (with moral symbol) or Masha (no moral symbol) to deliver the message, $\chi 2(1,47)=5.72, p<$. 05. In the control condition, 51.7 percent of participants (15 out of 29) asked Zoya to communicate the deceptive message. This percentage was significantly lower in the moral symbol condition, in which only 16.7 percent of participants (3 out of 18) asked Zoya to communicate the deceptive message. In other words, exposing a leader to moral symbols did prevent the superior specifically from asking the displayer to carry out the unethical 
action if they chose to do so in the ethical dilemma condition, however, the moral symbol did not impact the superior's choices in the no moral dilemma condition.

\section{STUDY 4}

Study 4 tests the underlying mechanism, moral awareness, responsible for the effect of exposure to moral symbols on reduction in unethical behavior (Hypotheses 1-2). Additionally, we investigate whether displaying moral symbols may have hidden backlash effects such that the superior may avoid the moral symbol displayer and may view such subordinate as an undesirable person to socialize with. To this end, we also measured possible backlash effects against those who display moral symbols.

\section{Methods}

Sample and Design. One hundred and forty participants were recruited from a nationwide database maintained by a university in United States. Eighteen individuals who failed to follow instructions, failed attention checks, or did not respond to questions regarding the study variables of interest were excluded from analyses. The final sample consisted of 122 participants (38 men, $M_{\text {age }}=33.7, S D=11.4$ ). The study employed a 2 condition (Moral symbol: present vs. absent) between subjects design.

Procedure. Participants engaged in a decision making task adapted from Schweitzer, DeChurch, and Gibson (2005) and also used by Pitesa and Thau (2013). This task is based on the principles of the prisoner's dilemma. All participants were assigned to the same role, which described how they had been promoted to an important division of a tours company. In order to make profits, it was important for the company to maximize the number of its tours. However, a competitor was operating in the same location and if both companies continued to increase the number of tours, the location would soon become less exotic and lose its appeal with tourists, 
thereby driving down future revenue. Further, participants were informed that they had just received an e-mail from one of their subordinates, Pat Anderson, sending them the numbers they requested about the decision at hand. They further read that their competitor had offered to match the number of tours that Roving Tours (i.e., the participant's company) would disclose to them. So, trying to minimize the number of tours run by the competitor by pretending that they would run only a few tours, but conducting more runs in actuality would lead to a higher payoff for their company. In other words, as with any prisoner's dilemma, the company could defect from the original number of stated tours to make more profit. The participant, in the role of the protagonist, had to decide what number of tours to directly communicate to the other team and decide privately what number to actually execute.

Based on random assignment, participants were exposed to either a moral quote or neutral quote at the bottom of their subordinate’s email. In the moral symbol condition, participants saw the moral quote, "Better to fail with honor than succeed by fraud.” In the control condition, they saw the neutral quote, “Success and luck go hand in hand.” Participants were informed that their company typically schedules between 1 to 7 tours for dry seasons. Next, participants indicated the number of tours that their company would actually run the following season, and, how many tours they would report to their competitor that they intend to run. The variable of interest was the difference between actual and stated number of tours, an act of purposeful deception and therefore an unethical decision. Note that the subordinate, Pat, was not part of the decision making nor part of the communication with the competitor company, and the participants would communicate the deceptive message themselves and their subordinate would not know whether the communication was honest or deceptive. 
We measured moral awareness with the three items $(\alpha=.82)$ from Reynolds (2006). A sample item was “The situation I was in clearly had some moral aspects to it.” Responses were coded on a scale from 1 (“Strongly disagree”) to 7 (“Strongly agree”).

Additionally, we measured potential backlash against the subordinate, Pat, with six items ( $\alpha$ $=.94$ ) adapted from Amanatullah and Tinsley (2013). Sample items are "How interested would you be in working with Pat?" "If you were the project manager on a work assignment, how likely would you be to ask Pat to be part of the project team?" and "How interested would you be in interacting socially with Pat?” Responses varied on a scale from 1 (“Not at all”) to 7 (“Extremely”).

\section{Results and Discussion}

Reduction in overall unethical behavior. We compared both the percentage of liars and the average lying (the difference between the reported tours and the actual numbers of tours intended to run) between conditions. First, we examined if exposure to a moral symbol led to a lower incidence of deceiving the competitor. Indeed, the percentage of participants who chose to misrepresent the number of tours varied based on whether they had been exposed to a moral symbol, $\chi^{2}(1,122)=3.05, p<.10$. In the control condition with neutral quote, 35.4 percent of participants (23 out of 65) chose to misrepresent themselves to their business competitor. This percentage was marginally significantly lower in the moral symbol condition, in which 21.1 percent of participants (12 out of 57) chose to engage in deception. So, the display of moral symbols reduced the unethical behavior of the leader overall.

Next, we examined whether exposure to the moral symbol influenced the extent of deception by examining the difference between the number of tours that participants claimed they would run and the number they intended to run. We conducted a linear regression with extent of deception as the dependent variable and exposure to moral symbol as the independent variable, $F(1,121)=4.01, p<.05$. The average amount of deception was lower among participants 
exposed to the moral symbol $(M=.30, S D=.71)$ compared to those in the control condition $(M=.66, S D=1.13)$. In brief, the analyses with both measures provide preliminary support for Hypothesis 1.

Moral awareness. We found that exposure to the moral symbol influenced reported moral awareness, $F(1,121)=7.13, p<.05$. Specifically, exposure to the moral symbol led to higher moral awareness among participants $(M=5.60, S D=1.04)$ than those exposed to the neutral quote $(M=5.03, S D=1.29)$.

Mediation by moral awareness. To test whether moral awareness mediated the effect of the display of moral symbols on the likelihood of superiors' unethical behavior we used the bootstrapping approach outlined by Preacher and Hayes (Preacher \& Hayes, 2004). Results of the bootstrapping analysis (with 5000 iterations) revealed that display of moral symbols had a statistically significant effect on moral awareness $(B=.57, p<.01)$, which in turn significantly affected the extent of unethical behaviors $(B=-.22, p<.01)$. Indeed, the effect of moral symbols was reduced (from $B=-.36, p<.05$, to $B=-.24$, n.s.) when moral awareness was included in the model. The bootstrap analysis offered support for Hypothesis 2 by demonstrating that the $95 \%$ bias-corrected confidence interval for the size of the indirect effect excluded zero (-.29, -.04). Running the analyses with the percentage of deceivers showed the same pattern with the 95\% bias-corrected confidence interval for the size of the indirect effect excluding zero (-.74, -.08).

Backlash against displayer of moral symbol. There was no significant difference between conditions on backlash $\left(M_{\text {moral }}=4.78, S D=1.42\right.$ vs. $\left.M_{\text {neutral }}=4.72, S D=1.26\right)$, $F(1,121)=.05$, n.s. This suggests that superiors do not avoid the moral symbol displayer and view such subordinate as desirable as another subordinate. 
The purpose of Study 5 was to use a simulation involving organizational decision-making and also to examine the role of inferences about the moral character of subordinates.

\section{Methods}

Sample and Design. Sixty-eight college students (40 men, $M_{\text {age }}=20.75, S D=1.67$ ) were recruited from United States to take part in this study for pay. The study employed a 2 condition (Moral symbol: present vs. absent) between subjects design.

Procedure. Participants were informed that they would participate in a simulation examining decision-making. The simulation task that they were asked to complete was adopted from an “in-basket exercise” developed by Brief, Dukerich, Brown, and Brett (1996). In this simulation, participants played the role of "Drew Meyer," the Joint-President of a software company called Silika, and contender for promotion to President. The role was designed such that Drew had authority over two senior vice presidents, Pat and Sam, in addition to other organizational members.

The simulation presented participants with background information about the company and their role, and required them to respond to emails in their inbox. Based on random assignment, participants were exposed to either a moral quote or neutral quote from one of their subordinates. While responding to their inbox, in the moral symbol condition, participants saw an email from Pat with the same moral quote used in previous studies, "Better to fail with honor than succeed by fraud.” In the control condition, they saw the quote, "Success and luck go hand in hand.” Participants viewed multiple emails and to avoid order effects, these emails were presented in a randomized order such that some participants saw an email from Sam first while others saw Pat's email first. 
Participants were presented with several filler emails after which they read a memorandum in which Drew Meyer (their role) were presented with an opportunity to ask either of the subordinates, Pat or Sam, to fraudulently report the company's finances and show a profit. Reporting fraudulent finances not only would materially increase the firm's profits for the year and increase Drew’s chances of making President, but also ensure that all organizational members received year-end bonuses. However, it was an unethical choice ${ }^{4}$. Participants then chose one of the options (to report the fraudulent finances or not) and decided who would carry out their request. Afterwards, they responded to some filler emails.

Next, participants were presented with 3 statements regarding Pat’s and Sam’s moral character respectively and asked to state their agreement with the statements on a scale of 1 (not at all true) to 5 (very true). Items included, "Pat/Sam is ethical," "Pat/Sam is moral,” and “Pat/Sam does not live by his/her principles” [reverse coded] ( $\alpha=.72)$.

\section{Results and Discussion}

Reduction in overall unethical behavior. We examined if exposure to a moral symbol led to reduction in overall unethical behavior (i.e., a lower incidence of sending the email to ask for fraudulent reporting of finances). We found that the percentage of participants who chose to send the email for deceptive accounting varied based on whether they had been exposed to a moral symbol, $\chi 2(1,68)=9.95, p<.01$. In the control condition with neutral quote, 67.6 percent of participants (23 out of 34) chose to engage in fraudulent reporting of finances. This percentage was significantly lower in the moral symbol condition, in which 29.4 percent of participants (10

\footnotetext{
${ }^{4}$ A pilot study with a separate group of participants $(n=58)$ confirmed that people judged reporting fraudulent accounts as less ethical $(M=1.63, S D=.93)$ than correcting the fraudulent report $(M=4.25, S D=.65), F(1,57)=$ 153.33, $p<001$.
} 
out of 34) chose to engage in deceptive accounting. So, the display of moral symbols reduced the unethical behavior of the leader overall, thus supporting Hypothesis 1.

Protection for displayer of moral symbols. To examine whether the moral symbol served as a protection mechanism for those displaying the symbols, once again, we examined the subset of participants who chose the unethical act. Indeed, among leaders who decided to behave unethically, exposure to the moral symbol had a significant effect on whether they chose Pat (subordinate displaying the moral symbol) or Sam (no moral symbol) to fraudulently report the company's finances, $\chi^{2}(1,33)=2.22, p<.05$. In the control condition, 70 percent of participants (16 out of 23) asked Pat to carry out their unethical directive. This percentage was significantly lower in the moral symbol condition, in which 20 percent of participants (2 out of 10) asked Pat to fraudulently report the company’s finances. So, exposing a leader to moral symbols did prevent the superior specifically from asking the displayer of a moral symbol to engage in unethical acts.

Perceived moral character of displayer of moral symbol ${ }^{5}$. We found that exposure to a moral symbol influenced people's perception of moral character of the displayer, $F(1,67)=$ 13.22, $p<.05$. Specifically, display of a moral symbol led participants to judge Pat to be more ethical $(M=3.91, S D=0.71)$ than those who saw a neutral quote $(M=3.24, S D=0.82)^{6}$.

\footnotetext{
${ }^{5}$ We intended to test Hypothesis 3 (mediation hypothesis) in this study, however given the low number of participants, who chose Pat to engage in unethical behavior $(n=2)$, the numbers are too low to appropriately test mediation, therefore, we do not present the mediation analyses in results section. However, using the bootstrapping approach outlined by Preacher and Hayes (Preacher \& Hayes, 2004), results revealed that display of moral symbol had a statistically significant effect on perceived morality of Pat $(\mathrm{B}=.68, p<.001)$, which in turn significantly affected the choice to ask Pat to carry the unethical order $(\mathrm{B}=-2.21, p<.05)$. Indeed, the effect of our manipulation was reduced (from $\mathrm{B}=1.61, p<.01$, to $\mathrm{B}=1.07, p<.10$ ) when perceived morality of Pat was included in the equation. The $95 \%$ bias-corrected confidence interval for the size of the indirect effect excluded zero $(.21,2.25)$, suggesting that the perceived morality of the person displaying the moral symbol mediated the effect of moral symbol display on the likelihood of superior asking the displayer to engage in unethical behavior.

${ }^{6}$ A pilot study with a separate group of participants $(\mathrm{n}=37)$ who did not complete the ethical decision making task and saw a neutral version of the task confirmed that people evaluated Pat as being more ethical in the experimental condition $(M=3.90, S D=.70)$ than in the control condition, i.e., email with a neutral quote $(M=3.30, S D=.96)$,
} 
However, Pat's display of a moral symbol had no effect on the perceived moral character of Sam, $F(1,67)=2.32$, n.s.

The results of Study 5 thus provide further support for the hypothesized effect of moral symbols, and in particular, in regard to the displayer. Additionally, this study provides some preliminary evidence in support of our argument for the effect of the inferences about the moral character of displayer of moral symbol on decisions.

\section{STUDY 6}

Thus far, we examined the effect of moral symbols in controlled experimental studies in which participants were exposed to a moral symbol momentarily and then interacted with the displayer. However, the validity of these findings and effectiveness of moral symbols would be enhanced more by testing the hypotheses in a field setting ripe with competing cues, conflicting goals, and high stakes. To this end, we examined if the results obtained in previous studies may be obtained in a real setting with subordinates and supervisors. We collected data from subordinate-supervisor dyads in which subordinates reported the criterion variable - unethical request- and the supervisors reported the predictor variable - exposure to moral symbols - to reduce common methods bias.

The additional organizational data with subordinate-supervisor dyads also help us demonstrate that our proposed effect results from perceived high moral character of the subordinate. Furthermore, this study provides a fertile ground to study if moral symbols would work despite the obvious power asymmetries in the real world.

Another advantage of this study is that we investigated the effect of examples of moral symbols already in use in business settings in an eastern culture. Specifically, we collected data

$F(1,36)=4.74, p<.05$. Furthermore, participants did not distinguish between Pat and Sam on non-moral attributes such as intelligence, competence, etc. 
in India in which pictures of gods and other religious icons as examples of moral symbols are frequently used in workplace. Prior literature has supported the idea that in most cultures and societies religious symbols are seen as moral symbols. For example, to prime morality, prior research has widely used religious reminders such as the Ten Commandments (e.g., Mazar et al., 2008). Mazar and colleagues note that "the idea of the Ten Commandments recall task was that independent of people's religion, of whether people believed in God, or of whether they knew any of the commandments, knowing that the Ten Commandments are about moral rules would be enough to increase attention to their own moral standards and thus increase the likelihood of behavior consistent with these standards” (p. 635). It is important to note that we did not equate religious symbols with moral symbols, rather argue that in most cultures and contexts, religious symbols could be perceived as moral symbols.

\section{Methods}

Data were collected from surveys administered to both employees and their supervisors in a variety of organizations in India. Business administration students of a business school in India approached the organizations and recruited them. In all, we obtained completed data from one hundred and four subordinate-supervisor pairs. The sample was drawn from a variety of professions, such as the IT sector, accounting, sales, and so forth. Regarding demographic characteristics, 63 percent of the employee respondents were male, and the mean age of the employee respondents was 31.44 years $(S D=9.19)$. The employee respondents had a mean job tenure of 4.39 years $(S D=1.40)$. Eighty-nine percent of the supervisor respondents were male, and the mean age of supervisor respondents was 41.44 years $(S D=6.08)$. The supervisors had a job tenure of 6.61 years $(S D=1.2)$. Moreover, they had interacted with their subordinates for an average of 3.37 years $(S D=1.08)$. 
The supervisor survey contained subordinate’s performance measure, a relationship quality measure, a question regarding whether the target employee displays moral symbols, the perceived moral character of the employee (counterbalanced), as well as demographic questions. The employee survey contained measures related to how frequently the supervisor issues unethical directives and how frequently the supervisor stops by their work desk (counterbalanced). Subordinates also answered questions regarding their job satisfaction, their position and demographic questions.

\section{Measures}

Unethical requests by supervisor. To measure incidence of unethical requests made by the supervisor at work, we used six items on a 7-point scale $(1=$ never, $7=$ all the time). Subordinates were asked to state their agreement/disagreement with statements about their current work, including "My boss asks me to do things that are morally inappropriate," "My boss asks me to do things that make me feel dirty afterwards," "My boss asks me to look the other way while he engages in questionable conduct," "My boss asks me to do tasks that involve lying to others," "My boss asks me to misrepresent facts to make him/her look good," and "My boss makes me treat some people disrespectfully.” The six items were averaged to form a composite score for unethical requests by the superior $(\alpha=.93)$. We conducted a confirmatory factor analysis (CFA) to ensure that this scale had appropriate statistical properties. Results suggested that all six items loaded on a single latent factor and the CFA supported the single-factor structure of the measure.

Display of moral symbols. The supervisors responded to a single, dichotomous item asking whether their subordinates display pictures of gods or other religious icons (such as Krishna, Jesus, Buddha) in their workspace (e.g., on their desks or walls of the cubicle). 
Perceived moral character of subordinate. The supervisors were asked to state their agreement with the three statements on a scale of 1 (not at all true) to 5 (very true). Items included, "The subordinate is ethical," "The subordinate is moral," and "The subordinate does not live by moral principles” [reverse coded] $(\alpha=.70)$.

Control variables. To eliminate the possibility that unethical requests could be explained by variables extraneous to our model, we measured and statistically controlled for other variables that seemed likely to influence unethical directives. Specifically, we controlled for the subordinate's and supervisor's age, gender, and job tenure. We also controlled for supervisorsubordinate tenure. We measured the degree of the supervisor's exposure to the moral symbol by a single item asking employees to indicate their agreement with the statement "My supervisor frequently stops by my work desk” on a 7-point scale ( 1 = strongly disagree, 7 = strongly agree). Additionally, we measured job satisfaction using a single item that asked employees how they felt about their job in general on a 7-point scale $(1=$ not at all satisfied, 7 = very satisfied $)$ (Desai, Sondak, \& Diekmann, 2011). Moreover, we measured job performance by asking superiors to evaluate their subordinates on three items adopted from Welbourne, Johnson, and Erez (1998). These items asked supervisors to assess the quantity, quality, and accuracy of the subordinate's work output on a 7-point scale ( 1 = very poor, 7 = excellent). The three items were averaged to form a composite score for job performance $(\alpha=.71)$. In addition, we measured religious affiliation of both the subordinate and supervisor, and created a dummy variable called religious dissimilarity that was coded 1 if the dyad members did not belong to the same religion. Controlling for religious dissimilarity would help to rule out for confounds based on the similarity-attraction effect (Byrne, London \& Reeves, 1968). We also created a dummy variable called gender dissimilarity that was coded 1 if the dyad members belonged to the same gender 
categories and 0 for mixed dyads. Lastly, we measured relationship quality between the superior and subordinate by using a shortened version of the leader-member-exchange (LMX) scale (Graen \& Uhl-Bien, 1995). Supervisors responded to five items that asked them to assess the quality of their relationship with their subordinate on a 7-point scale $(1=$ very poor, $7=$ excellent). The five items were averaged to form a composite score for relationship quality ( $\alpha=$ $.80)$.

\section{Results}

Descriptive statistics and correlations among study variables are presented in Table 1. As noted in the table, 43 percent of subordinates displayed some form of moral symbol. For instance, these symbols could be pictures of Krishna, Rama, Buddha, Mahavir, Sai Baba, Jesus, Virgin Mary, or even rosary beads for prayers and quotes from the Koran. Importantly, display of a moral symbol was positively correlated with perceived moral character of the subordinate $(r=.42, p<.001)$ and negatively correlated with unethical requests $(r=-.31, p<.01)$.

[Insert Table 1 Here]

Perceived moral character of displayer of moral symbol. We conducted a regression analysis with perceived moral character of displayer as the criterion variable and display of moral symbols at work as the predictor variable while including all the control variables. We found that exposure to a moral symbol in the form of religious symbols was associated with supervisors' perception of the moral character of the subordinate (beta $=.37, p<.001$ ). Specifically, display of a moral symbol was related to supervisors' higher assessments of their subordinate's moral character compared to those with no such displays.

Protection for displayer of the moral symbols. To test our hypothesis, we conducted a multiple regression analysis predicting unethical requests. We regressed the criterion variable on 
display of moral symbols at work while including control variables. Hypothesis 3 was supported, as unethical requests were negatively related to the display of moral symbols ( beta $=-.24, p<$ .05) as shown in Model 1 of Table 2. Moreover, male supervisors were less likely to make unethical requests ( beta $=-.22, p<.05$ ), and older subordinates were less likely to be issued unethical directives (beta $=-.25, p<.01$ ) . Importantly, upon introducing the mediator, perceived moral character of the subordinate, the effect of display of moral symbols on unethical requests was reduced to non-significance, thereby suggesting mediation (Model 2, Table 2).

[Insert Table 2 Here]

Mediation by perceived moral character of the displayer. To test whether perceived moral character of the displayer mediated the effect of the display of a moral symbol on the likelihood of superior issuing unethical directives we used the bootstrapping approach outlined by Preacher and Hayes (Preacher \& Hayes, 2004). Results of the bootstrapping analysis (with 5000 iterations) revealed that display of moral symbol had a statistically significant effect on perceived moral character of the subordinate $(B=.87, p<.01)$, which in turn significantly affected unethical requests by supervisors $(B=-.34, p<.01)$. Indeed, the effect of moral symbols was reduced (from $B=-.72, p<.05$, to $B=-.42$, n.s.) when perceived moral character of the subordinate was included in the equation. The bootstrap analysis offered support for Hypothesis 4 by demonstrating that the $95 \%$ bias-corrected confidence interval for the size of the indirect effect excluded zero (-.61, -.03). Note that these results were obtained while controlling for religious dissimilarity and its two-way interaction with moral symbol. In other words, even in instances where a superior belonged to a different religion, the religious symbols displayed by the subordinate altered the superior's perception about the moral character of the subordinate and discouraged them from issuing unethical directives. 


\section{GENERAL DISCUSSION}

In this paper, we examined one possible way employees can influence organizational authorities' ethical behavior and discourage unethical directives—by displaying moral symbols. In the studies presented here, the presence of moral symbols did not necessarily provide any explicit additional monitoring or clear economic deterrent for behaving unethically, yet the exposure discouraged unethical behavior. In the laboratory studies, participants, as the team leader, had the opportunity to act unethically themselves or ask a team member to deceive others. In each of these studies, the presence of a moral symbol served to reduce the incidence of own unethical behavior and unethical directive to others. Our work suggests that exposure to moral symbols increases moral awareness, which in turn, reduces unethical behavior. Furthermore, the person displaying the moral symbol is perceived to be of high moral character, and thus is less likely to be asked to engage in unethical behavior. The consistency of findings across our experimental studies and the organizational survey provides robust support for our theory.

\section{Theoretical and Practical Implications}

This research makes several contributions to the literature on ethical decision-making. First, the present work extends previous research in behavioral ethics in organizations by focusing on a bottom up perspective to examine how employees may influence superiors. Existing research in this field for the most part has taken a top down perspective and examined how organizational authorities can influence employees (e.g., Palmer, 2008; Schaubroeck et al., 2012; Treviño \& Brown, 2004). For example, the primary focus of the ethical leadership literature has been on its consequences (Mayer et al., 2012; Schaubroeck et al., 2012). However, in conceptualizing ethical leadership, Brown, Treviño and Harrison (2005) relied on social learning theory which suggests that individuals learn by paying attention to the attitudes, values, 
and behaviors of others. Importantly, it is not just followers who can learn from ethical leaders; leaders can also learn from followers. Thus, having a moral follower can change a leader's behavior or values and attitudes. In spite of theoretical arguments for the effect of followers on the leader's ethicality (Hernandez \& Sitkin, 2012), relatively little empirical research exists. We are among the first to suggest and provide evidence that the use of moral symbols by followers can change the perception of the situation at hand and elicit inferences about the moral character of the displayer and thus, followers can guide their leaders' behavior and reduce the occurrence of unethical acts in the workplace.

Second, this work adds to the small but growing body of research which considers the role of interpersonal influence in behavioral ethics (Moore \& Gino, 2013). A large body of work shows that moral identity internalization and symbolization guide individuals’ own actions (e.g., Aquino \& Reed, 2002; Shao, Aquino, \& Freeman, 2008; Winterich, Aquino, Mittal, \& Swartz, 2013). However, it is not clear whether the use of moral symbols can impact interpersonal dynamics by serving as a form of social influence. We have argued that exposure to moral symbols can elicit certain judgments and cognitions regarding the situation at hand as well as the displayer, and in turn, this can influence the targets' behavior in general and their actions towards the displayer, thereby serving a social regulatory function. There is research demonstrating that people's ethical decisions are influenced by how others in their immediate surrounds behave. For instance, studies have shown that if people observe an in-group member (e.g., a person from the same college) cheating, their likelihood of cheating increases; however, if the person observed cheating belongs to an out-group, people are less likely to cheat (Gino, Ayal, \& Ariely, 2009; Gino, Gu, \& Zhong, 2009). 
Third, it contributes to the ongoing conversation regarding the importance of moral character in the workplace (e.g., Cohen, Panter, Turan, Morse, \& Kim, 2014). Whereas extant work has demonstrated that employees classified as high moral character are less likely to commit harmful work behaviors and more likely to engage in prosocial organizational behaviors than their counterparts who are of low moral character, our work demonstrates how inferring that a subordinate has high moral character can influence his or her supervisor's ethical behavior. Thus, our works suggests that there might be second order effects of moral character. We provided evidence for the role of inferences about the moral character of the displayer as an underlying psychological mechanism explaining how moral symbols influence supervisors’ behavior. This is important because even though the increase in moral awareness suggests an overall decrease in unethical behavior, it does not predict the differentiation between requesting the displayer versus other subordinates.

Fourth, our work fills a void in the ethical leadership literature by investigating how subordinates influence their leader's ethical behavior. Our findings lend credence to the idea that other people’s expressed moral character can serve to activate leaders’ moral awareness and cause them to behave in a manner consistent with ethical standards. This is in line with prior theoretical arguments conceptualizing ethical leadership as a social learning process (Brown \& Treviño, 2006) as well as social information processing models (Salancik \& Pfeffer, 1978) that emphasize the role of context in decision making, more generally. Furthermore, we provide empirical support for Hernandez and Sitkin's (2012) model in which they propose that followers can influence their leader's ethicality in indirect and implicit ways. Our findings also contribute more generally to the leadership literature. There is a burgeoning movement within the leadership literature to explore more deeply the intersection of the domains of leadership and 
identity (van Knippenberg, van Knippenberg, De Cremer, \& Hogg, 2004). This body of work has emphasized the importance of understanding how and why facets of followers' identities constitute boundary conditions of leadership effects. Here, we have examined how a subordinate's moral identity (as inferred by the display of moral symbols) shapes the leader's behavior and in turn, how this influences follower outcomes in the form of fewer unethical directives.

Fifth, our research contributes to the literature on how social influence impacts individuals' ethical decisions. Previous research has examined the effects of different contextual factors, organizational ethical culture (Treviño et al., 1998) and peer pressure from unethical coworkers (Ashforth \& Anand, 2003; Gino et al., 2009). In this paper, for the first time, we demonstrate that ethical nudges in the form of moral symbols have a powerful impact on individual decision making. Our work demonstrates that subtle forms of social influence such as moral symbols can influence decision makers regardless of their power. This has important implications given that ethical influences can occur in the context of power differences in organizations. Thus, our work suggests power does not always shield the decision maker from social influence.

Sixth, while extensive research has examined the effects of moral identity (both internalization and symbolization) on individuals' behaviors (e.g., Aquino \& Reed, 2002), less empirical work has examined the consequences for actions of others exposed to such displays. In this paper, we examined how moral symbols can act as a form of social influence by impacting ethical behaviors of others. Furthermore, extant research on the effects of moral primes has not examined whether repeated exposure to such cues increases or decays their strength. Our field 
study suggests that the effects of moral symbols may not wane over time due to repeated exposure.

Finally, fear of retaliation is the primary reason for employees being generally reluctant to report work-rated transgressions (Miceli et al., 2013). And a large body of research acknowledges how difficult it is to “just say no” to a boss (Rolloff \& Paulson, 2001; Treviño \& Brown, 2004; Uhl-Bien \& Carsten, 2007). Some recent research has identified that unethical behavior can be curbed by the use of explicit interventions such as introducing a code of ethics (Weaver, Treviño, \& Cochran, 1999). The present work highlights the role that subtle interventions, such as the display of moral symbols, play in producing similar results. We also show that the use of moral symbols does not bring hidden backlash effects against those who display them. We offer a way to help employees to guide the leader's behavior and avoid doing the unethical. Given that moral symbols appear to be relatively inexpensive, coupling them with formal ethics programs might improve the ethical climate of workplaces.

\section{Limitations and Future Directions}

This research is not without its fair share of shortcomings. First, though it demonstrates successfully the powerful effect of moral symbols, a number of our studies were conducted in controlled, laboratory environments. Some researchers have commented that because of the artificiality so characteristic of experimental settings, research done in the laboratory is limited in its ability to help us understand organizational phenomena. Critics of this stance have countered that laboratory research can offer powerful tests of conceptual propositions, including propositions of behavior in real-world organizations (e.g., Weick, 1965). Given that this paper explored for the very first time the effectiveness of moral symbols in preventing those in authority from issuing unethical directives, employing laboratory studies was reasonable. 
Moreover, after conducting the laboratory studies, we tried to establish the generalizability of the findings by employing a diverse sample, namely employees in India. However, the robustness of these findings would be enhanced even more by testing the hypotheses in field settings in the western cultures such as the United States.

It is important to note that even though our hypotheses focused on moral symbols displayed by subordinates, the “increased moral awareness” mechanism would suggest that mere exposure to the symbols should be sufficient, even if not displayed by a subordinate. For example, seeing your boss or even just a random person on the street with a t-shirt with a moral word might produce the proposed effect. In other words, the effect may be broader than our studies show.

It is also possible that exposing superiors, especially the unethical ones, to moral symbols may result in undesirable side-effects. This may result in various forms of retaliation against that employee such as not being included in important decisions or work activities, being passed over for a raise or promotion, being relocated or reassigned to less desirable positions, or even being laid off. Even though in Study 6, there was no significant difference in the supervisor's formal evaluation of the subordinate's job performance as a function of whether the subordinate was a displayer of moral symbols, and in Studies 3-4 there seemed to be no detrimental side effects of displaying such symbols, yet it might be helpful for future studies to systematically examine the full consequences of the use of moral symbols in workplace.

An additional issue that warrants further examination is that though exposure to moral symbols may cause the boss to make fewer unethical requests overall, if the boss does make an unethical request, it will be more likely to be directed towards those not displaying such symbols thereby resulting in a form of collateral damage. In other words, there might be incidental 
negative consequences for others, and future work should explore possible ways that organizations can combat them. For instance, could organizations incorporate into their culture a few moral symbols that convey powerful meanings, and would doing so impart a stronger, shared value system such that even "non-display" employees come to be protected from unethical requests?

In the laboratory studies described in this paper, the forms of unethical behaviors studied were chiefly of the pecuniary kind, where the supervisors stood to benefit monetarily by behaving unethically. Self-interested unethical behaviors were curbed by the display of moral symbols. However, it is unclear if the display of moral symbols may also result in a reduction in other forms of unethical behavior such as gender or racial discrimination or sexual harassment. Exploring a full spectrum of morally questionable workplace behaviors would be a helpful next step.

As a first step, it was helpful to examine across laboratory studies the effects of two particular types of moral symbol, namely, a moral quotation at the bottom of an email and one's clothes. Additionally, we examined the effect of using religious symbols as one type of moral symbols. However, it would be worthwhile to examine whether other forms of moral symbols are equally effective. Another possible venue for future work might be to examine the role of morality-related personality variables such as, moral identity (Aquino \& Reed, 2002), moral chronicity (Lapsley \& Navarez, 2004), and moral self-importance (Colby \& Damon, 1992), as moderators of the effect of moral symbols on ethical decision making. Moreover, future work could explore how and why inferring that a subordinate is moral dissuades supervisors from making unethical requests. 
Also, throughout the paper, we side-stepped the issue of whether the displayers of moral symbols are actually moral. It is possible that people may be motivated to hide their true moral identities by strategically using moral symbols as an impression management technique (Bolino, 1999). For example, Barkan, Ayal, Gino and Ariely (2012) found that the recall of unethical events motivated participants in a lab experiment to try and present themselves as moral when filling out a scale related to their own morality. Future work should explore the motivations and cognitions of those who display such symbols. Moreover, future work should examine whether the intentions behind the display of moral symbols influence their effectiveness. More specifically, it would be helpful to tease apart possible differences in the ways in which authentic and naturally occurring displays operate compared to displays that are intentional and strategic. For example, would an inauthentic representation of oneself by wearing a cross despite not being religious still serve to ward off unethical requests?

Lastly, we would like to note that whereas we were able to identify a positive effect of the display of moral and religious symbols in the workplace, we acknowledge that there might be a dark side associated with such displays. For instance, people who display such symbols may become prey to self-serving assessment biases and end up feeling “feeling holier-than-thou” (Epley \& Dunning, 2000) or provide vicarious moral credentials for the superior (Kouchaki, 2011). Such feelings might subsequently result in moral self-licensing and possible unethical behavior (Merritt, Effron, \& Monin, 2010).

\section{CONCLUSION}

In closing, this paper offers a promising solution to the problem of how to reduce the incidence of unethical behavior and requests in workplace. The results of the studies presented here show that by exposing superiors to moral symbols subordinates may lower overall instances 
of unethical behaviors at work, and also dissuade superiors from asking them (i.e., subordinates displaying moral symbols), in particular, to engage in unethical behaviors. Exposure to moral symbols leads to the activation of the concept of morality to increase individuals' moral awareness as well as to inferences about the moral character of the displayer, both guiding moral behavior and reducing the occurrence of unethical acts in the workplace. 


\section{REFERENCES}

Amanatullah, E. T., \& Tinsley, C. H. 2013. Punishing female negotiators for asserting too much... or not enough: Exploring why advocacy moderates backlash against assertive female negotiators. Organizational Behavior and Human Decision Processes, 120(1): $110-122$.

Anderson, C. A., Benjamin, A. J., \& Bartholow, B. D. 1998. Does the gun pull the trigger? Automatic priming effects of weapon pictures and weapon names. Psychological Science, 9: 308-314.

Aquino, K., \& Reed, A. II. 2002. The self-importance of moral identity. Journal of Personality and Social Psychology, 83: 1423-1440.

Aquino, K., Freeman, D., Reed II, A., Lim, V. K., \& Felps, W. 2009. Testing a social-cognitive model of moral behavior: the interactive influence of situations and moral identity centrality. Journal of Personality and Social Psychology, 97(1): 123-141.

Ashforth, B. E., \& Anand, V. 2003. The normalization of corruption in organizations. Research in organizational behavior, 25: 1-52.

Bargh, J. A. 1994. The Four Horsemen of automaticity: Awareness, intention, efficiency, and control in social cognition. In R. S.Wyer, Jr., \&T. K. Srull (Eds.), Handbook of social cognition (2nd ed., pp. 1-40). Hillsdale, NJ: Erlbaum.

Bargh, J. A. 2007. Social psychology and the unconscious: The automaticity of higher mental processes. Philadelphia, PA: Psychology Press.

Barkan, R., Ayal, S., Gino, F., \& Ariely, D. 2012. The pot calling the kettle black: Distancing response to ethical dissonance. Journal of Experimental Psychology: General, 141(4): 757-773.

Belk, R. W. 1988. Possessions and the extended self. Journal of Consumer Research, 15(2): 139-168.

Bolino, M.C. 1999. Citizenship and impression management behavior: Good soldiers or good actors? Academy of Management Journal, 24(1): 82-98.

Brief, A. P., Dukerich, J. M., Brown, P. R., \& Brett, J. F. 1996. What's wrong with the Treadway Commission report? Experimental analyses of the effects of personal values and codes of 
conduct on fraudulent financial reporting. Journal of Business Ethics, 15: 183-198.

Brown, M. E., \& Treviño, L. K. 2006. Ethical leadership: A review and future directions. The Leadership Quarterly, 17(6): 595-616.

Brown, M. E., Treviño, L. K., \& Harrison, D. A. 2005. Ethical leadership: A social learning perspective for construct development and testing. Organizational Behavior and Human Decision Processes, 97(2): 117-134.

Byrne, D., London, O., \& Reeves, K. 1968. The effects of physical attractiveness, sex, and attitude similarity on interpersonal attraction. Journal of Personality, 36(2): 259-271.

Cohen, T. R., Panter, A. T., Turan, N., Morse, L. A., \& Kim, Y. 2014. Moral character in the workplace. Journal of Personality and Social Psychology, 107(5): 943-963.

Colby, A., \& Damon, W. 1992. Some do care: Contemporary lives of moral commitment. New York: The Free Press.

Cushman, F., Young, L., \& Hauser, M. 2006. The role of conscious reasoning and intuition in moral judgment testing principles of harm. Psychological science, 17(12): 1082-1089.

Desai, S. D., \& Kouchaki, M. 2015. Work-report formats and overbilling: How unit-reporting vs. cost reporting increases accountability and decreases overbilling. Organizational Behavior and Human Decision Processes, 130: 79-88.

Desai, S. D., Sondak, H., \& Diekmann, K. A. 2011. When fairness neither satisfies nor motivates: The role of risk aversion and uncertainty reduction in attenuating and reversing the fair process effect. Organizational Behavior and Human Decision Processes, 116: 32-45.

Dittmar, H. (1992). The social psychology of material possessions: To have is to be. United Kingdom: Harvester Wheatsheaf.

Elsbach, K.D. 2003. Relating physical environment to self-categorizations: A study of identity threat and affirmation in a non-territorial office space. Administrative Science Quarterly, 48: 622-654.

Elsbach, K.D. 2004. Interpreting workplace identities: The role of office decor. Journal of Organizational Behavior, 25: 99-128.

Elsbach, K. D., \& Pratt, M. G. 2007. Effects of the physical environment in corporate work 
settings. In J. Walsh \& A. Brief (Eds.), Academy of Management Annual (Vol. 1), Mahwah, NJ: Lawrence Erlbaum.

Epley, N., \& Dunning, D. 2000. Feeling "Holier Than Thou”: Are self-serving assessments produced by errors in self- or social prediction? Journal of Personality and Social Psychology, 79: 861-875.

Ethics Resource Center. 2013. National business ethics survey: Workplace ethics in transition. Retrieved on Nov. 12, 2013 from http://www.ethics.org/nbes/

Gino, F., Ayal, S., \& Ariely, D. 2009. Contagion and differentiation in unethical behavior: The effect of one bad apple on the barrel. Psychological Science, 20: 393-398.

Gino, F., \& Desai, S. D. 2012. Memory lane and morality: How childhood memories promote prosocial behavior. Journal of Personality and Social Psychology, 102(4): 734-758.

Gino, F., Gu, J., \& Zhong, C. B. 2009. Contagion or restitution? When bad apples can motivate ethical behavior. Journal of Experimental Social Psychology, 45: 1299-1302.

Gneezy, U. 2005. Deception: The role of consequences. American Economic Review, 95: 384394.

Gollwitzer, P. M. 1986. Striving for specific identities: The social reality of self-symbolizing. R. Baumeister, ed. Public Self and Private Self. New York: Springer-Verlag.

Gosling, S. D., Ko, S. J., Mannarelli, T., \& Morris, M. E. 2002. A room with a cue: Personality judgments based on offices and bedrooms. Journal of Personality and Social Psychology, 82: 379-398.

Graen, G. B., \& Uhl-Bien, M. 1995. Relationship-based approach to leadership: Development of leader-member exchange (LMX) theory of leadership over 25 years: Applying a multilevel multi-domain perspective. The Leadership Quarterly, 6(2): 219-247.

Graham, J., Nosek, B. A., Haidt, J., Iyer, R., Koleva, S., \& Ditto, P. H. 2011. Mapping the moral domain. Journal of Personality and Social Psychology, 101: 366-385.

Greene, J. D., Nystrom, L. E., Engell, A. D., Darley, J. M., \& Cohen, J. D. 2004. The neural bases of cognitive conflict and control in moral judgment. Neuron, 44(2): 389-400. 
Greene, J. D. 2009. Dual-process morality and the personal/impersonal distinction: A reply to McGuire, Langdon, Coltheart, and Mackenzie. Journal of Experimental Social Psychology, 45(3): 581-584.

Greene, J., \& Haidt, J. 2002. How (and where) does moral judgment work? Trends in cognitive sciences, 6(12): 517-523.

Gunia, B.C., Wang, L., Huang, L., Wang, J., \& Murnighan, J.K. (2012). Contemplation and conversation: Subtle influences on moral decision making. Academy of Management Journal, 55(1): 13-33.

Haidt, J. 2001. The emotional dog and its rational tail: a social intuitionist approach to moral judgment. Psychological review, 108(4): 814.

Hernandez, M. \& Sitkin, S. B. 2012. Who is leading the leader? Follower influence of leader ethicality. In D. De Cremer \& A. Tenbrunsel (Eds.), Behavioral Business Ethics: Shaping an Emerging Field (pp. 81-102).New York: Rutledge.

Kay, A. C., Wheeler, S. C., Bargh, J. A., \& Ross, L. 2004. Material priming: The influence of mundane physical objects on situational construal and competitive behavioral choice. Organizational Behavior and Human Decision Processes, 95: 83-96.

Kern, M. C., \& Chugh, D. 2009. Bounded Ethicality The Perils of Loss Framing. Psychological Science, 20(3): 378-384.

Kohlberg, L. 1981. The philosophy of moral development moral stages and the idea of justice.

Kouchaki, M. 2011. Vicarious moral licensing: the influence of others' past moral actions on moral behavior. Journal of personality and social psychology, 101(4): 702-715.

Kouchaki, M., Smith-Crowe, K., Brief, A. P., \& Sousa, C. 2013. Seeing green: Mere exposure to money triggers a business decision frame and unethical outcomes. Organizational Behavior and Human Decision Processes, 121(1), 53-61.

Lapsley, D. \& Narvaez, D. 2004. A social-cognitive view of moral character. In D. Lapsley \& D. Narvaez (Eds.), Moral development: Self and identity (pp. 189-212). Mahwah, NJ: Erlbaum.

Laughlin, H. P. 1970. The ego and its defenses. New York: Appleton-Century-Crofts. Lerner, J. S., \& Tetlock, P. E. 1999. Accounting for the effects of accountability. Psychological 
Bulletin, 125: 255-275.

Mayer, D. M., Aquino, K., Greenbaum, R. L., \& Kuenzi, M. 2012. Who displays ethical leadership and why does it matter? An examination of antecedents and consequences of ethical leadership. Academy of Management Journal, 55(1): 151-171.

Mazar, N., Amir, O., \& Ariely, D. 2008. The dishonesty of honest people: A theory of selfconcept maintenance. Journal of Marketing Research, 45(6): 633-644.

Merritt, A. M., Effron, D. A., \& Monin, B. 2010. Moral self-licensing: When being good frees us to be bad. Social and Personality Psychology Compass, 4: 344-357.

Mesmer-Magnus, J. R., \& Viswesvaran, C. 2005. Whistleblowing in organizations: An examination of correlates of whistleblowing intentions, actions, and retaliation. Journal of Business Ethics, 62(3): 277-297.

Miceli, M. P., Near, J. P., \& Dworkin, T. M. (2013). Whistle-blowing in organizations. Psychology Press.

Miller, D. T. 1998. Material cultures: Why some things matter. London, England: UCL Press. Monin, B., Pizarro, D., \& Beer, J. 2007. Deciding vs. reacting: Conceptions of moral judgment and the reason-affect debate. Review of General Psychology, 11: 99-111.

Moore, C., \& Gino F. 2015. Approach, ability, aftermath: A psychological process model to understand unethical behavior at work. Academy of Management Annals, 9, 235-289.

Moore, C., \& Gino, F. 2013. Ethically adrift: How others pull our moral compass from true North, and how we can fix it. Research in Organizational Behavior, 33: 53-77.

Palmer, D. 2008. Extending the process model of collective organizational wrongdoing. Research in Organizational Behavior, 28: 107-135.

Pitesa, M. \& Thau, S. 2013. Compliant sinners, obstinate saints? How power and self-focus determine the effectiveness of unethical social influences. Academy of Management Journal, 53: 635-658.

Preacher, K. J., \& Hayes, A. F. 2004. SPSS and SAS procedures for estimating indirect effects in simple mediation models. Behavior Research Methods, Instruments, \& Computers, 36(4): 717-731.

Rest, J. R. 1986. Moral development: Advances in research and theory. Praeger Publishers. 
Reynolds, S. J. 2006. A neurocognitive model of the ethical decision-making process: implications for study and practice. Journal of Applied Psychology, 91: 737-748.

Rolloff, M. E., \& Paulson, G. D. 2001. Confronting organizational transgressions. In J. M. Darley, D. M. Messick, \& T. R. Tyler (Eds.), Social influences on ethical behavior in organizations (pp. 55-70). Mahwah, NJ: Taylor \& Francis.

Salancik, J., \& Pfeffer, G. 1978. A social information processing approach to job attitudes and task design. Administrative Science Quarterly, 23(2): 224-53.

Schaubroeck, J. M., Hannah, S. T., Avolio, B. J., Kozlowski, S. W., Lord, R. G., Treviño, L. K., \& Peng, A. C. 2012. Embedding ethical leadership within and across organization levels. Academy of Management Journal, 55(5): 1053-1078.

Schweitzer, M. E., DeChurch, L. A., \& Gibson, D. E. 2005. Conflict frames and the use of deception: Are competitive negotiators less ethical? Journal of Applied Social Psychology, 35: 2123-2149.

Shantz, A., \& Latham, G. P. 2009. An exploratory field experiment of the effect of subconscious and conscious goals on employee performance. Organizational Behavior and Human Decision Processes, 109: 9-17.

Shao, R. D., Aquino, K., Freeman, D. 2008. Beyond moral reasoning: A review of moral identity research and its implications for business ethics. Business Ethics Quarterly, 18(4): 513540.

Shweder, R. A., Mahapatra, M., \& Miller, J. 1987. Culture and moral development. In J. Kagan \& S. Lamb (Eds.), The emergence of morality in young children (pp. 1-83). Chicago: University of Chicago Press.

Shweder, R. A., \& Much, N. C. 1991. Determinations of meaning: Discourse and moral socialization. In R. A. Shweder (Ed.), Thinking through cultures (pp. 186-240). Cambridge, MA: Harvard University Press.

Sonenshein, S. 2007. The role of construction, intuition, and justification in responding to ethical issues at work: The sense making-intuition model. Academy of Management Review, 32(4): 1022-1040.

Stoker, B. 1897/2011. Dracula. Barnes \& Noble. 
Tahmincioglu, E. 2000, May 17. Caught between payday and principle. New York Times, Extracted from http://www.nytimes.com/2000/05/17/jobs/caught-between-payday-andprinciple.html

Tenbrunsel, A. E., \& Messick, D.M. 1999. Sanctioning systems, decision frames, and cooperation. Administrative Science Quarterly, 44: 684-707.

Tenbrunsel, A. E., \& Smith-Crowe, K. 2008. Ethical decision making: Where we've been and where we're going. The Academy of Management Annals, 2(1): 545-607.

Treviño, L. K. 1986. Ethical decision making in organizations: A person-situation interactionist model. Academy of management Review, 11(3): 601-617.

Treviño, L. K., \& Brown, M. E. 2004. Managing to be ethical: Debunking five business ethics myths. Academy of Management Executive, 18: 69-81.

Treviño, L. K., Butterfield, K. D., \& McCabe, D. L. 1998. The ethical context in organizations: Influences on employee attitudes and behaviors. Business Ethics Quarterly, 8(03): 447476.

Uhl-Bien, M., \& Carsten, M. 2007. Being ethical when the boss is not. Organizational Dynamics, 36(2): 187-201.

van Knippenberg, B., van Knippenberg, De Cremer, D., \& Hogg, M A. 2004. Leadership, self, and identity: A review and research agenda. The Leadership Quarterly, 15: 825-856.

Walker, L. J., \& Hennig, K. H. 2004. Differing conceptions of moral exemplarity: Just, brave, and caring. Journal of Personality and Social Psychology, 86: 629-647.

Weaver, G. R., Treviño, L. K., \& Cochran, P. 1999. Integrated and decoupled corporate social performance: Management commitments, external pressures, and corporate ethics practices. Academy of Management Journal, 42: 539-552.

Weick, K. E. 1965. Laboratory experimentation with organizations. In J. G. March (Ed.), Handbook of organizations. Chicago: Rand McNally.

Welbourne, T. M., Johnson, D. E., \& Erez, A. 1998. The role-based performance scale: Validity analysis of a theory-based measure. Academy of Management journal, 41(5): 540-555.

Welsh, D., \& Ordóñez, L. D. 2014. Conscience without cognition: The effects of subconscious priming on automatic ethical behavior. Academy of Management Journal, 57: 723-742. 
Winterich, K. P., Aquino, K., Mittal, V., \& Swartz, R. 2013. When Moral identity symbolization motivates prosocial behavior: The role of recognition and moral identity internalization. Journal of Applied Psychology, 98(5): 759-770. 
Table 1. Descriptive statistics and correlations for Study 6.

\begin{tabular}{|c|c|c|c|c|c|c|c|c|c|c|c|c|c|c|c|c|c|}
\hline Variable & Mean & s.d. & 1 & 2 & 3 & 4 & 5 & 6 & 7 & 8 & 9 & 10 & 11 & 12 & 13 & 14 & 15 \\
\hline $\begin{array}{l}\text { 1. Unethical } \\
\text { directives }\end{array}$ & 2.95 & 1.49 & & & & & & & & & & & & & & & \\
\hline $\begin{array}{l}\text { 2. Moral } \\
\text { symbol }\end{array}$ & 0.43 & 0.50 & $-0.31 * *$ & & & & & & & & & & & & & & \\
\hline $\begin{array}{l}3 . \\
\text { Subordinate } \\
\text { gender }\end{array}$ & 0.63 & 0.48 & 0.04 & -0.02 & & & & & & & & & & & & & \\
\hline $\begin{array}{l}4 . \\
\text { Subordinate } \\
\text { age }\end{array}$ & 31.44 & 9.19 & $-0.30 * *$ & 0.16 & 0.07 & & & & & & & & & & & & \\
\hline $\begin{array}{l}5 . \\
\text { Subordinate } \\
\text { job tenure }\end{array}$ & 4.39 & 1.40 & -0.09 & -0.05 & 0.00 & -0.07 & & & & & & & & & & & \\
\hline $\begin{array}{l}6 . \\
\text { Supervisor } \\
\text { gender }\end{array}$ & 0.89 & 0.31 & $-0.26 * *$ & $0.24^{* *}$ & -0.07 & -0.05 & $-0.17^{*}$ & & & & & & & & & & \\
\hline $\begin{array}{l}7 . \\
\text { Supervisor } \\
\text { age }\end{array}$ & 41.44 & 6.08 & 0.11 & -0.02 & $-0.17 *$ & 0.00 & 0.04 & -0.10 & & & & & & & & & \\
\hline $\begin{array}{l}8 . \\
\text { Supervisor } \\
\text { job tenure }\end{array}$ & 6.61 & 1.20 & -0.10 & -0.13 & 0.00 & -0.06 & $0.50 * * *$ & 0.00 & $-0.17^{*}$ & & & & & & & & \\
\hline $\begin{array}{l}9 . \\
\text { Supervisor- } \\
\text { subordinate } \\
\text { tenure }\end{array}$ & 3.37 & 1.08 & -0.15 & 0.09 & -0.06 & 0.06 & $0.78 * * *$ & -0.09 & 0.10 & $0.45^{* * *}$ & & & & & & & \\
\hline $\begin{array}{l}10 . \text { Job } \\
\text { satisfaction }\end{array}$ & 4.34 & 1.63 & -0.05 & 0.08 & -0.11 & 0.12 & -0.14 & -0.01 & -0.10 & -0.15 & -0.09 & & & & & & \\
\hline $\begin{array}{l}\text { 11. Job } \\
\text { performance }\end{array}$ & 4.47 & 1.03 & 0.15 & 0.15 & -0.02 & -0.04 & -0.01 & 0.05 & -0.02 & 0.05 & -0.02 & $0.25^{* *}$ & & & & & \\
\hline $\begin{array}{l}12 . \\
\text { Religious } \\
\text { dissimilarity }\end{array}$ & 0.13 & 1.09 & -0.09 & 0.11 & -0.13 & -0.02 & -0.02 & 0.01 & 0.07 & -0.08 & 0.04 & -0.13 & -0.14 & & & & \\
\hline
\end{tabular}


13.

Relatio

quality

14.

Perceived

moral

character of

subordinate

15. Gender

dissimilarity

$\begin{array}{lll}0.42 & 0.49 \quad 0.07\end{array}$

$-0.02$

$-0.78 * * * \quad 0.01$

$-0.06$

$-0.22 *$

$0.26 * *$

$-0.06$

0.00

0.07

0.04

$0.14 \quad 0.17^{*} \quad-0.04$

16. Degree

of exposure

0.05

$-0.14$

$-0.14$

$-0.09$

$-0.07$

0.03

$-0.11$

$-0.11$

$0.21^{*}$

0.16

$0.19 *$

$-0.17$

0.05

0.13

$N=104$ dyads. $* p<.05 .{ }^{* *} p<.01 .{ }^{* * *} p<.001$. Gender was coded 1 for males and 0 for females for both supervisors and subordinates. 
Table 2. Results of regression with unethical requests as the criterion variable (Study 6).

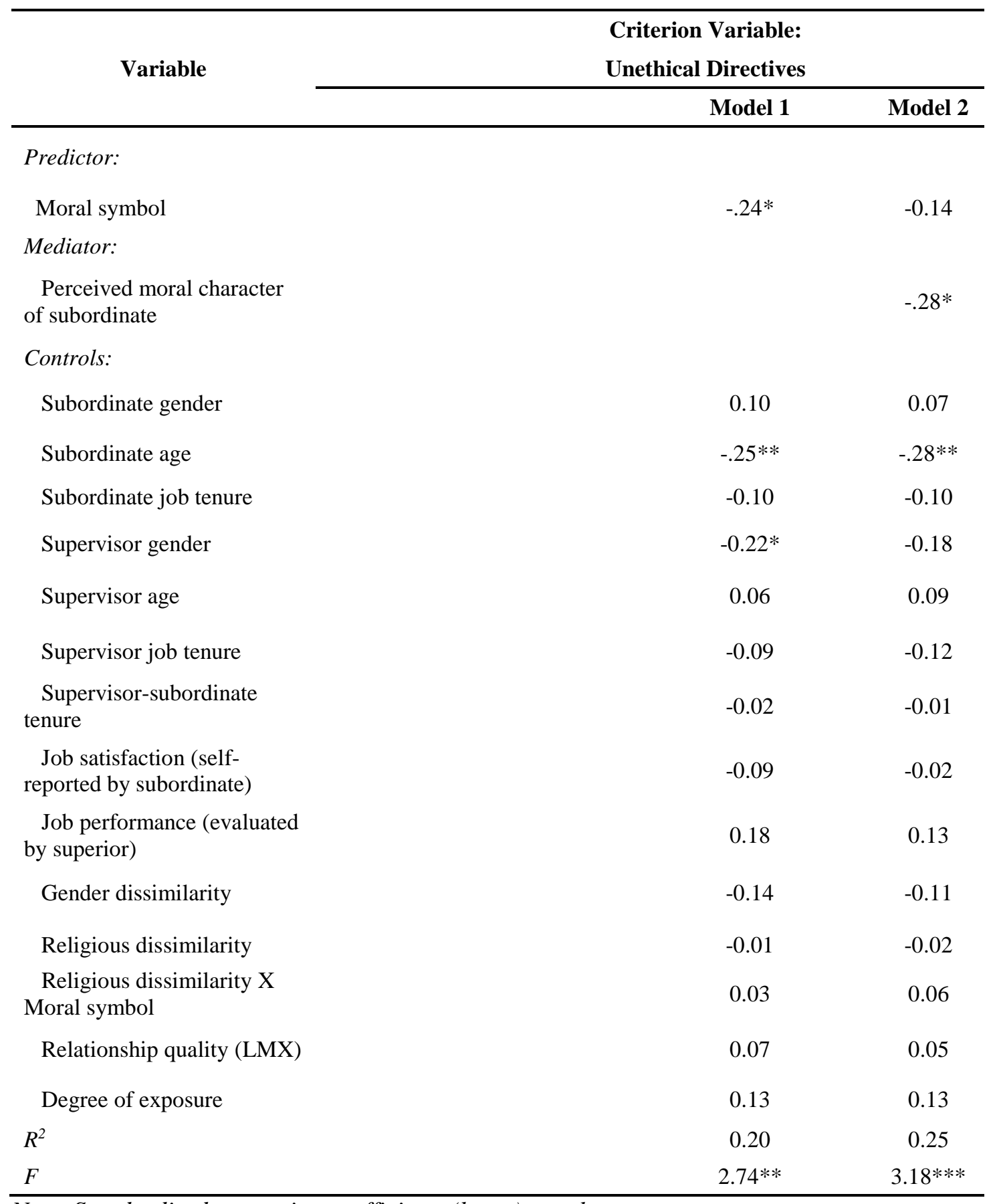

Note. Standardized regression coefficients (betas) are shown.

${ }^{*} p<.05{ }^{* *} p<.01 .{ }^{* * *} p<.001$. 
Figure 1. Theoretical model for the link between display of moral symbols and moral decisions. Display of moral symbols leads to two main consequences: (i) increased moral awareness, in general, and (ii) perception that the displayer has high levels of moral character.

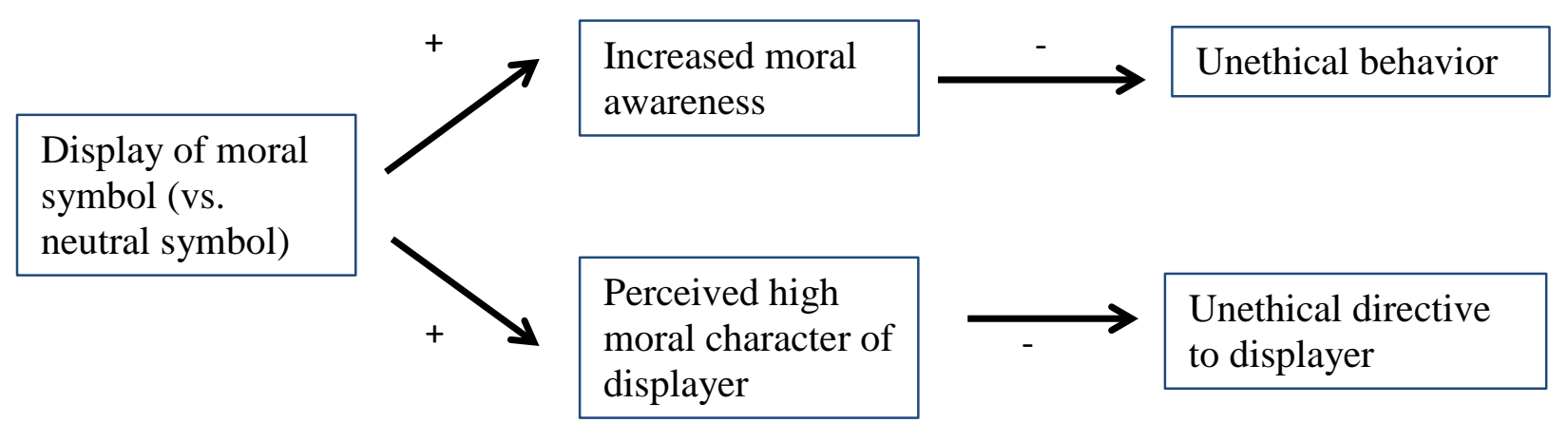

